ISSN 2072-6694

www.mdpi.com/journal/cancers

Review

\title{
Targeted Radionuclide Therapy
}

\section{Devrim Ersahin *, Indukala Doddamane and David Cheng}

Department of Diagnostic Radiology, School of Medicine, Yale University, 333 Cedar St., New Haven, CT 06520, USA; E-Mails: indukala.doddamane@yale.edu (I.D.);david.cheng@yale.edu (D.C.)

* Author to whom correspondence should be addressed; E-Mail: devrimersahin@yahoo.com; Tel.: +1-215-290-5917; Fax: +1-203-200-5054.

Received: 22 August 2011; in revised form: 27 September 2011 / Accepted: 27 September 2011 / Published: 11 October 2011

\begin{abstract}
Targeted radiotherapy is an evolving and promising modality of cancer treatment. The killing of cancer cells is achieved with the use of biological vectors and appropriate radionuclides. Among the many advantages of this approach are its selectiveness in delivering the radiation to the target, relatively less severe and infrequent side effects, and the possibility of assessing the uptake by the tumor prior to the therapy. Several different radiopharmaceuticals are currently being used by various administration routes and targeting mechanisms. This article aims to briefly review the current status of targeted radiotherapy as well as to outline the advantages and disadvantages of radionuclides used for this purpose.
\end{abstract}

Keywords: targeted radiotherapy; radionuclide; radioimmunotherapy

\section{Introduction}

The development and evolution of modern chemotherapy during the second half of the twentieth century has improved the clinical outcome of patients with various forms of cancer [1]. Still, in the vast majority of malignancies, the efficacy of systemic chemotherapy is very limited, with $90 \%$ of all drug cures occurring in only $10 \%$ of cancer types [2].

Unlike systemic chemotherapy, the goal of targeted radiotherapy is the selective delivery of radiation to cancer cells in a way that causes minimal toxicity to surrounding normal tissues. The basis for successful radionuclide therapy is selective concentration and prolonged retention of the radiopharmaceutical within the tumor. Tumor response depends on numerous factors, including cumulative radiation dose delivered, dose penetration, and tumor radiosensitivity. The radiation effect is 
maximally achieved when the radiation dose is entirely absorbed by the tumor. In practice however, this is almost never the case because of biologic turnover.

\section{Radiopharmaceuticals and Targeting Mechanisms}

The selection of the appropriate radionuclide depends on its nuclear decay properties, specifically, emission characteristics and physical half-life. The treatment of bulky tumors by radionuclides that emit high energy alpha or beta particles is the preferred approach (Tables 1 and 2); however, for the eradication of small clusters of cancer cells or small tumor deposits, radionuclides that emit Auger electrons are considered to be beneficial because of their high level of cytotoxicity and short-range biological effectiveness [3].

Table 1. Most commonly used radionuclides for targeted radiotherapy in US [4,5].

\begin{tabular}{llllll}
\hline Radionuclide & $\begin{array}{l}\text { Physical } \\
\text { half life }\end{array}$ & $\begin{array}{l}\text { Emission type } \\
\text { (energy in keV) }\end{array}$ & $\begin{array}{l}\text { Range in } \\
\text { tissue }(\mathbf{m m})\end{array}$ & Advantages & Disadvantages \\
\hline I-131 & $8.04 \mathrm{~d}$ & $\begin{array}{l}\text { Beta }(\max 606) \\
\text { and gamma }(364)\end{array}$ & $2.5-3$ & $\begin{array}{l}\text { Availability } \\
\text { Low cost } \\
\text { Easy labeling }\end{array}$ & $\begin{array}{l}\text { High radiation burden } \\
\text { to family members and } \\
\text { medical personnels }\end{array}$ \\
\hline Y-90 & $64 \mathrm{~h}$ & Beta $(\max 2280)$ & 12 & $\begin{array}{l}\text { High-energy } \\
\text { beta-emission } \\
\text { Prolonged tumor } \\
\text { retention }\end{array}$ & Bone marrow toxicity \\
\hline Sm-153 & $46.3 \mathrm{~h}$ & $\begin{array}{l}\text { Beta }(\max 807) \\
\text { and gamma }(103)\end{array}$ & 3 & $\begin{array}{l}\text { Short range in } \\
\text { tissue }\end{array}$ & Bone marrow toxicity \\
\hline Sr-89 & $50.5 \mathrm{~d}$ & Beta $(\max 1463)$ & 8 & Easy labeling & $\begin{array}{l}\text { Long half life } \\
\text { Bone marrow toxicity }\end{array}$ \\
\hline
\end{tabular}

Table 2. Commonly used radiopharmaceuticals for targeted therapy.

\begin{tabular}{lll}
\hline Radiopharmaceutical & Targeting mechanism & Indications \\
\hline I-131 as iodide & Thyroid hormone synthesis & $\begin{array}{l}\text { Differentiated thyroid } \\
\text { carcinomas }\end{array}$ \\
\hline I-131 Tositumomab & CD20 Antigen binding & Non-Hodgkin's lymphoma \\
\hline Y-90 Ibritumomab tiuxetan & CD20 Antigen binding & Non-Hodgkin's lymphoma \\
\hline Y-90 microspheres & Intravascular trapping & $\begin{array}{l}\text { Liver metastasis } \\
\text { Hepatocellular carcinoma }\end{array}$ \\
\hline Sr-89 chloride & Calcium analogue & Bone pain palliation \\
\hline Sm-153 EDTMP & Chemoadsorption & Bone pain palliation \\
\hline Y-90 Octreotide & Somatostatin receptor binding & Neuroendocrine tumors \\
\hline & Active transport into & $\begin{array}{l}\text { Neuroblastoma } \\
\text { Pheochromacytoma } \\
\text { Carcinoid }\end{array}$ \\
I-131 MIBG & intracellular storage & $\begin{array}{l}\text { Paraganglioma } \\
\text { Medullary thyroid carcinoma }\end{array}$ \\
\hline
\end{tabular}




\section{I-131 Treatment for Thyroid Cancer}

Treatment of differentiated thyroid cancer (DTC) with radioactive iodine (RAI) is the oldest and most common targeted radiotherapy used in the United States and worldwide. It aims at destroying residual microscopic tumor tissue to reduce the recurrence rate, ablating remaining thyroid tissue to optimize follow-up conditions (e.g., thyroglobulin measurement), and completing staging by a highly sensitive post-therapeutic whole-body scintigraphy [6]. Papillary and follicular thyroid cancers generally express the sodium iodide symporter, which is the key cellular feature for specific uptake of radioactive iodine $[7,8]$.

Following a total or near total thyroidectomy with or without lymph node dissection, RAI ablation of remnant thyroid tissue with I-131 facilitates long term surveillance using serum thyroglobulin measurements. Generally, I-123 whole body scan (WBS) is used prior to therapy to evaluate uptake in the remnant thyroid tissue. This scan can also evaluate the presence of pulmonary and skeletal metastases. The American Thyroid Association (ATA) guidelines published in November 2009, suggest that a pre-therapy I-123 WBS is not necessary for stages I and II or low risk patients since empiric dosing is often not affected by the results [9]. However, based on our clinical experience in our institution, we recommend obtaining an I-123 WBS scan prior to RAI treatment.

According to ATA guidelines, RAI ablation following the initial postoperative management of DTC is recommended for patients with stage III or IV disease, most patients with stage II disease age $<45$ years and all patients with stage II disease age 45 years or older, selected patients with stage I disease especially those with multifocal disease ( $\geq 2$ foci , at least one of them $>1 \mathrm{~cm}$ ), nodal metastases, extrathyroidal or vascular invasion, and/or more aggressive histologies (e.g., tall cell, insular, columnar cell carcinoma) [9].

RAI dose is usually determined empirically. Suggested dose for remnant ablation in low risk patients is $30-100 \mathrm{mCi}$. When residual microscopic disease is suspected or there is more aggressive tumor histology, higher doses (100-200 mCi) may be appropriate. Recent studies suggest that there are no statistical differences in 5 year outcome using low or high doses of I-131 ranging between 30-100 $\mathrm{mCi}$ in remnant ablation in low risk DTC patients [10,11]. However, in a study by Kukulska et al., 22\% of such patients who initially received $30 \mathrm{mCi}$ required a second course of treatment for complete ablation [10]. One study by Maxon et al. suggested that I-131 treatment alone can effectively treat tumor foci that exhibit iodine uptake, as long as a radiation dose of at least $80 \mathrm{~Gy}$ is delivered; doses below 35 Gy do not usually bring about a desirable response [12]. Response to I-131 treatment is also dependent on the sensitivity of the tumor to radiation, with younger patients having greater responses as a result of well-differentiated tumors and smaller lesions $(<1 \mathrm{~cm}$ in diameter) [13].

An alternative approach to fixed dosing is an individualized dosing based on remnant uptake or lesion and bone marrow dosimetry prior to therapy. For this, the European Association of Nuclear Medicine (EANM) Dosimetry Committee recently published a standard operation procedure. General guideline is to deliver tumor doses exceeding $80 \mathrm{~Gy}$ and absorbed dose to blood should be below 2 Gy [14,15].

In case of recurrent or persistent DTC, surgical resection is usually considered as the first line of treatment. In this case, RAI therapy is an effective alternative and/or adjuvant treatment option for cure, symptom palliation, and decreasing tumor burden. According to EANM guidelines, nonresectable metastatic lymph nodes, pulmonary micrometastases, nonresectable or incompletely operable 
macrometastases in the lungs and nonresectable soft-tissue metastases are definite indications for recurrent RAI therapy. Furthermore, optional fields of application include recurrent radioiodinesensitive lymph node and distant metastases (adjuvant role), nonresectable small and/or multiple lymph node metastases, inoperable bone metastases, micrometastases, and anaplastic or poorly differentiated thyroid cancer with relevant well-differentiated portions and thyroglobulin ( $\mathrm{Tg}$ ) expression [16].

Patient preparation prior to treatment is necessary to maximize iodine uptake. In order to achieve elevated serum thyroid stimulating hormone (TSH) levels, patients are either withdrawn from their thyroid hormone replacement or given recombinant human TSH (rhTSH) intramuscularly. In most institutions, patients are advised to follow a low iodine diet for 1-2 weeks before I-131 administration.

Elevated serum TSH level $(>30 \mathrm{mU} / \mathrm{L})$ is desirable to increase the sensitivity of detection using imaging modalities or tumor marker $\mathrm{Tg}$, to increase the efficacy of I-131 radioiodine ablation of thyroid remnant in patients who have undergone a total or near total thyroidectomy and for curative or palliative treatment of metastatic thyroid cancer. Patients often experience symptoms of hypothyroidism including fatigue, depression, and decreased cognitive function, which may impact their daily activities significantly. In a study by Pacini et al., patients who were withdrawn had a lower quality of life, and had difficulty performing work because of physical health issues [17]. Traditionally, elevated serum TSH is achieved by hormone withdrawal, which may take 4-6 weeks. The duration of hormone withdrawal symptoms can be shortened with T3 supplement during this period and weaned for only $8-10$ days prior to treatment. A similar rise is serum TSH can be achieved within a shorter period from total hormone withdrawal. Alternatively, rhTSH can bypass these symptoms and should be considered for low risk patients. Some studies have shown a lower radiation burden to non-thyroidal tissues when treatment was performed under rhTSH stimulation as compared to hormone withdrawal. Currently, there is insufficient data to recommend rhTSH mediated therapy for all patients with metastatic disease being treated with RAI [9].

Generally accepted selection criteria for RAI treatment in patients with metastases include younger age, well-differentiated tumor histology, high RAI uptake, smaller metastases, location in lungs, stable or slow progressive disease, low uptake of F-18 FDG, and repeated RAI treatment (response rate: $85 \%$, with $96 \%$ of complete responses seen with a cumulative activity $<600 \mathrm{mCi}$ ) [18]. One of the major concerns with high treatment doses compared to relatively lower doses of I-131 for thyroid cancer includes their immediate and long term side effects on salivary glands and oral cavity. In addition, concerns also have been raised for secondary malignancies especially following multiple therapies. However, there has been conflicting data as to whether treatment with I-131 increases this type of risk. Given the lack of comparison or control groups, the reliability of a few published articles in this regard is questionable $[19,20]$. RAI treatment has been a widely accepted treatment modality in the management of thyroid cancer across the world and will continue to do so, given its effectiveness and safety profile.

\section{Y-90 Ibritumomab Tiuxetan and I-131 Tositumomab for Lymphoma Treatment}

Despite chemotherapeutic advances, numerous patients with low grade lymphoma still die from their disease [21]. Radiolabeled anti-CD20 antibodies Y-90 ibritumomab tiuxetan and I-131 tositumomab have been introduced within the past decade, yielding response rates of 50-80\% in patients with diseases refractory to other treatment modalities $[22,23]$. Ibritumomab is a murine $\operatorname{IgG}_{1}$ antibody $(\mathrm{Ab})$ that targets 
the $\mathrm{CD} 20$ antigen. Tositumomab is an $\mathrm{IgG}_{2 \mathrm{a}}$ murine anti-CD20 Ab, but differs from ibritumomab in how it is linked to the radionuclide. Both of these differ from rituximab (Rituxan; IDEC/Genentech), which is a hybrid Ab targeting a cluster of epitopes of the CD20 antigen, except on mature plasma cells. The CD20 antigen is found on the surface of pre-B lymphocytes, mature B lymphocytes and more than $90 \%$ of B-cell non-Hodgkin's lymphoma (NHL) [24,25]. The antibody recognizes epitopes in the extracellular domain of the CD20 antigen, and forms on antibody-antigen immune complex, which induces apoptosis, complement-dependent cytotoxicity, and antibody-dependent cytotoxicity [26,27].

Application of nonradioactive antibodies increases the therapeutic window of radioimmunotherapy (RIT) by increasing tumor to background ratio. Monoclonal antibodies (mAb) administered intravenously target cells to promote cell death. However, bioavailability of a small mass quantity of radioactively labeled mAb may be diverted from the tumor to normal B-cells in the circulation or spleen. Administering a pharmacologic quantity of nonradioactive $m A b$ prior to RIT administration will occupy and "mask" the antigen on normal B-cells in the blood and spleen and allow the radioactive antibodies to better access malignant B-cells. This ensures high bioavailability at tumor sites and reduces the radioactivity retained in the body. This concept of pre-targeting follows the principle of radiotracer kinetics in the field of nuclear medicine. The unbound radioactive molecules will clear rapidly from the blood and tissues, thus reduce radiation induced toxicity to normal organs, especially the bone marrow. It will also enhance the tumor-to background ratio and the delivery of a higher therapeutic dose [28].

Y-90 Ibritumomab tiuxetan is a novel radioimmunotherapeutic agent for the treatment of relapsed or refractory low-grade, follicular or CD20+-transformed NHL [28]. Y-90 Ibritumomab tiuxetan combines the tumor-specific targeting from $\mathrm{mAb}$ with the tumorcidal effect of radiation within a small volume. A large prospective phase III trial by Morschhauser et al. showed high efficacy with no unexpected toxicities in the setting of consolidation first-line therapy [29]. This study led to the approval of Y-90-ibritumomab tiuxetan in both Europe and in the United States in September 2009.

In general, both ibritumomab and tositumomab treatments are well tolerated. The most common side effect in patients previously treated with chemotherapy is severe cytopenia due to reversible myelosuppression. Similar efficacy and toxicity profiles are expected from both agents, including the development of human anti-mouse antibodies (HAMA), in patients with an intact immune system in particular. Repeated exposure will increase the risk. Formation of the HAMA-antibody complexes can dramatically reduce the bioavailability and thus targeting efficiency [30]. I-131-Tositumomab differs from Y-90-ibritumomab tiuxetan in that I-131-tositumomab has unlabelled "cold" antibody added in the preparation, whereas Y-90-ibritumomab tiuxetan has "cold" chimeric rituximab as the additive. This may help explain why Y-90-ibritumomab tiuxetan demonstrated HAMA or HACA (human anti-chimeric antibody) rate is $2 \%$ [31], while it is significantly higher (10\%) in relapsed patients treated with I-131 tositumomab. When I-131 tositumomab was used as first line treatment, the reported incidence was even higher at $65 \%$, attributable to an intact robust immune system [32].

Another major difference between Y-90-ibritumomab tiuxetan and I-131-tositumomab is the method in determining the therapeutic dose. In the United States, a pre-therapy scan with In-111-ibritumomab tiuxetan is used to assess a safe biodistribution of the radioactive Y-90-ibritumomab tiuxetan. Imaging is performed to confirm the expected biodistribution of the radioimmunoconjugate and not used for the assessment of tumor uptake. If pre-therapy biodistribution is acceptable, treatment dose is calculated based on patient's platelet counts and body weight up to a maximum of $32 \mathrm{mCi}$ total dose. Each dose of 
the radiolabeled antibody administration is preceded by an infusion of rituximab to assure the biodistribution of the radioimmunoconjugate [33].

On the other hand, a dosimetry study is performed to calculate the prescribed dose of I-131 tositumomab. The gamma photon emission from the I-131 allows pre-therapy imaging and patient-specific dose calculation patient-specific maximally tolerated whole body radiation dose taking into account variability in the rate of antibody clearance from each individual [34]. The amount of radioactivity for RIT may be determined by several methods, including those based on whole-body retention and on radiation burden to the limiting organ. The goal of each approach is to deliver maximum amount of radioactivity as tolerated by the critical organs. A retrospective study by Rajendran et al., based on a review of 100 patients' records showed that a dosimetry method based on whole-body retention may underestimate the organ doses. They concluded that a preferable approach may be organ-specific dosimetry [35].

Many studies demonstrated the efficacy of Y-90-ibritumomab tiuxetan and I-131 tositumomab to be similar in patients with chemotherapy- refractory low-grade relapsed NHL, with an overall response rate of $60 \%-83 \%$ and a complete response (CR) rate of $15-52 \%$ [31,36-41]. Song et al., using Monte Carlo based dosimetry in patients with lung metastases, found that I-131 may provide a therapeutic advantage over Y-90, especially in tumors with a radius less than $2.0 \mathrm{~cm}$, as well as with a lower tumor burden due to a shorter pathlength of the beta particle from I-131 radionuclide [42]. The biologic effects of radiation therapy may lag behind those of chemotherapy. Jacene et al. found that a positive response at 12 weeks after RIT correlated with long-term overall survival and proposed performing the initial assessment at this time point was reasonable. However, a watch-and-wait approach could be taken for those with a partial response (PR), near-CR, or CR, because latent responses may occur beyond 12 weeks after therapy. For patients who have not responded by 12 weeks, alternative therapies may be initiated [43]. PET/CT imaging before and after the treatment has been shown to be useful in the evaluation of treatment response as well as in staging and follow-up of tumors, particularly useful in lymphoma patients [44].

Radiolabeled monoclonal antibodies have been shown to be effective in patients with chemotherapy-refractory, low-grade, or transformed low-grade NHL [32]. Witzig et al. demonstrated that patients with indolent histologies, lower tumor grade, fewer than twosites of disease, and less bulky $(<7 \mathrm{~cm})$ disease were more likely to respond to Y-90-ibritumomab tiuxetan [39]. On the other hand, Fisher et al. showed that advanced age, prior radiotherapy, less than a 75-cGy dose of total-body radiation, bulky disease ( $\geq 5 \mathrm{~cm}$ ), prior anthracycline-containing chemotherapy regimens, and no response to the last chemotherapeutic regimen are predictive of a lower overall response rate [45]. Kaminski et al. found that a single course of I-131 tositumomab as initial therapy can induce $75 \%$ complete remission in patients with advanced follicular lymphoma, and patients who had both a CR and molecular response, as determined by the lack of BCL2 gene rearrangement in the bone marrow, had a progression-free survival of five years. Their findings suggest that this subset of patients may not benefit from additional or more intensive treatments [23].

Treatment-related myelodysplastic syndromes and acute myeloid leukemia is a well-known delayed complication in patients with low grade NHL [46]. This is thought to be due to repetitive exposure to cytotoxic drugs over a relatively long natural history of the disease. The success of RIT inducing durable remissions in patients with relapsed and refractory NHL can extend the period of observation for bone 
marrow disease. However, it will be important to separate the effects of RIT from the total incidence of treatment-related myelodysplastic syndromes and acute myeloid leukemia [47].

Lymphoma treatment using RIT appears to be generally well-tolerated and effective in selected groups of patients. Further clinical investigations are needed to increase its applications to other patient groups.

\section{Peptide Receptor Radionuclide Therapy for Neuroendocrine Tumor Treatment}

Somatostatin receptor expression in majority of gastroenteropancreatic neuroendocrine tumors (GEPNET) offers the opportunity for radiopeptide therapy using radiolabeled somatostatin analogues. Radiolabeled somatostatin analogues, such as octreotide, with a high affinity to sub-classes of this receptor have been in use for identification of somatostatin receptor-positive tumors for decades [48]. Clinical peptide receptor radionuclide therapy (PRRT) studies are being performed using different agents. [In-111-diethylenetriaminepentaacetic acid (DTPA)]-octreotide was the first analog introduced [49-52], followed by [Y-90dodecanetetraacetic acid (DOTA), Tyr3]octreotide (Y-90-DOTATOC) [51,53-55] , [Y-90-DOTA]-lanreotide [56], and [Lu-177-DOTA, Tyr3]octreotate [57,58].

Radiopeptides incorporating Indium-111, Yttrium-90, or Lutetium-177 have demonstrated both biochemical and radiologic responses in phase I and phase II studies. Despite the potential of this approach, there is still little consensus on the optimal isotope and dose for these agents. Rigorous studies focusing on including inclusion criteria and dosing procedures are needed to better define their role in treatment [59]. Indium-111 emits gamma photons at 172 and $245 \mathrm{keV}$, which can be used for scintigraphy. Auger electrons, with tissue penetration of 0.02 to $10 \mu \mathrm{m}$, and conversion electrons with tissue penetration of 200 to $500 \mu \mathrm{m}$, are also emitted. Therefore, it was thought that the high doses of In-111-DTPA may be useful for PRRT. In a phase I study by Valkema et al. involving 40 patients treated with In-111-DTPA-octreotide, the efficacy in large neuroendocrine tumors was low, with minimal efficacy in end-stage patients [60].

Bone marrow toxicity with In-111-DTPA-octreotide treatment has been observed at cumulative doses above $100 \mathrm{GBq}(2.7 \mathrm{Ci}$ ), and hence, this is considered to be the maximal tolerable dose. Valkema et al. suggested that dosing beyond this limit should be weighed between an improved quality of life and the risk of severe adverse effects to the bone marrow [60]. Side effects observed by Anthony et al. include discomfort at the injection site, thrombocytopenia, anemia, hepatotoxicty, nephrotoxicity, neurotoxicty, and musculoskeletal pain, all of which were transient [61]. However, the lack of response in lower doses and limited toxicity in their patients warranted dose escalation studies. Serious side effects observed by Valkema et al. were leukemia and myelodysplastic syndrome in patients treated with total cumulative doses of $>100 \mathrm{GBq}$ (2.7Ci) [60]. Since kidneys express several subtypes of the somatostatin receptor [62], they are at risk for toxicity.[Y-90-DOTA0,Tyr3]Octreotide demonstrated a higher affinity for somatostatin receptor subtype 2 with a greater stability than with an In-111 radionuclide. Different protocols have been used and despite some differences, complete or partial response rates are similar at 10-30\%, which is better than In-111-DTPA-octreotide. In a multicenter study by Valkema et al., patients treated with [Y-90-DOTA0,Tyr3] octreotide were given escalating doses up to $14.8 \mathrm{GBq} / \mathrm{m} 2$ $(400 \mathrm{mCi} / \mathrm{m} 2)$ in four cycles up to $9.3 \mathrm{GBq} / \mathrm{m} 2(250 \mathrm{mCi} / \mathrm{m} 2)$ each dose, without reaching the maximum tolerated single dose [63]. Bushnell et al. reported a favorable clinical response as determined by a scoring system, which included weight, patient-assessed health score, Karnofsky score, and 
tumor-related symptoms, in 14/21 patients treated with a total cumulative dose of $360 \mathrm{mCi}$ [Y-90-DOTA0,Tyr3] octreotide in three cycles [64].

Kwekkeboom et al. demonstrated the uptake of radioactivity, expressed as a percentage of the injected dose of [Lu-177-DOTA0,Tyr3]octreotate, was comparable to [In-111-DTPA0]octreotide in kidneys, spleen, and liver, but was found to be three- to four folds higher in four of five tumors with the exception of papillary thyroid carcinoma. This profile can deliver a higher dose to tumors while sparing the dose-limiting organs. Another advantage of Lu-177 over Y-90 is its shorter range of the beta particle in tissue (2 mm versus $12 \mathrm{~mm}$, respectively) [65].

In a study by Kwekkeboom et al., response rate when patients with GEPNET were treated with [Lu-177-DOTA0,Tyr3] octreotate was found to be 46\%. This number included the patients with minimal response (MR, defined as $>25 \%$ but $<50 \%$ reduction in tumor size) in addition to patients with PR and CR. They also noted a subclass of MR patients with slow growing GEPNET and often with a partly cystic appearance. In fact, the fraction of patients with PR (28\%) was greater when compared to CR (16\%) or MR (2\%) [66].

According to European Neuroendocrine Tumor Society (ENETS) guidelines published in 2009, response to PRRT should be evaluated by a combination of symptomatic and biochemical responses along with imaging response. CT or MRI can be used in follow-up imaging, but neither can provide information on functionality in cystic or necrotic tumors [67].

Up to one-third of metastasized or recurrent differentiated thyroid cancers (DTC) may dedifferentiate over time, characterized by the loss of growth-regulating mechanisms governed by TSH and/or a decline in iodine avidity protecting them from RAI therapy $[68,69]$. This effect is commonly attributed to a loss or reduced expression of the thyroidal sodium/iodide symporter. Targeted radiotherapy with somatostatin analogues is a potential treatment option for inoperable non iodine-avid DTC. However, intramuscular injection of long-acting octreotide for six months in eight patients with progressive non-iodine-avid but somatostatin receptor-positive thyroid cancer did not yield a significant therapeutic response [70].

Although results with [Y-90-DOTA0,Tyr3]octreotide and [Lu-177-DOTA0,Tyr3]octreotate appear promising, reported varied response rates. Factors limiting direct comparison of many studies include: study design (retrospective), non-randomization of patients, lack of control group, and heterogeneity in treatment population and dosing. Furthermore, variability in response criteria (e.g., imaging, symptomatic relief, as well as hormonal and biochemical responses) made comparison inequitable.

\section{I-131-Metaiodobenzylguanidine Therapy of Neuroblastoma and Other Neuroendocrine Tumors}

For almost three decades, I-131-metaiodobenzylguanidine (MIBG) has been used as a treatment option for NET. It has been shown to be efficacious in chromaffin (neuroblastoma, pheochromocytoma, and paraganglioma) as well as for carcinoid and other less common tumors. Uptake of MIBG, a norepinephrine analogue, in tissue reflects rich adrenergic innervation and/or catecholamine excretion [71-73].

Neuroblastoma is the most common extracranial childhood tumor, and it is very radiosensitive. Most stage I and II patients are treated by surgery alone. Stage III patients are given neoadjuvant 
chemotherapy prior to surgery. I-131 MIBG therapy is usually considered for stage III and IV patients. In addition to tumor growth control, symptomatic relief can be sought.

Treatment planning involves a staging workup including ultrasonography, CT or MRI studies, FDG-PET/CT, I-123-MIBG scintigraphy, and tissue biopsies. A bone marrow biopsy is also necessary to assess bone marrow failure in neuroblastoma, which is an absolute contraindication for I-131-MIBG treatment. Another absolute contraindication is renal failure, since this will decrease radiotracer clearance and prolong internal radiation exposure. Relative contraindications include incontinence and radiation protection considerations for family members and the public. Life expectancy of the patient to be treated should be greater than one month. Other considerations should include discontinuing medications that might interfere with MIBG uptake, including calcium channel blockers, sympathomimetics, and reserpine. The thyroid gland should be protected with potassium iodide or perchlorate administration prior to treatment.

I-131-MIBG should be infused over a period of at least one hour to avoid the severe acute side effects of the MIBG itself. The infusion system should be shielded to reduce radiation exposure of the staff. In addition, sunlight exposure of the MIBG should be avoided. During the infusion, vital signs have to be closely monitored by the staff or an automatic blood pressure measuring system, since blood pressure changes during the infusion are common. Subsequently, patient should receive a copious amount of intravenous fluid to facilitate excretion and minimize radiation exposure [74]. It should be noted that more than $50 \%$ of the given dose will be excreted with urine during the initial 48 hours $[75,76]$. This is especially important in the pediatric age group to avoid urine contamination in order to minimize the radiation exposure to the staff. Bladder catheterization can be considered for this reason. Acute and subacute side effects include nausea and/or vomiting, thrombocytopenia and less commonly leukopenia. In a phase II study by Matthay et al., a group of patients with refractory neuroblastoma were treated with $18 \mathrm{mCi} / \mathrm{kg}(0.66 \mathrm{GBq} / \mathrm{kg})$ I-131 MIBG and one third of the patients demonstrated hematopoietic toxicity requiring autologous hematopoietic stem cell support. Nonhematologic high grade toxicity was rare, with $5 \%$ of the patients experiencing hepatic, $3.6 \%$ pulmonary, and $10.9 \%$ infectious complications, as well as $9.7 \%$ with febrile neutropenia [77].

Other tumors that may benefit from I-131 MIBG therapy include pheochromocytoma, paraganglioma $[78,79]$, medullary thyroid cancer [80], and carcinoid tumors $[81,82]$ with response rates varying between $30 \%$ and $75 \%$. In a retrospective study of 37 patients treated with I-131 MIBG in a total of 116 treatment sessions, the overall survival rate was $85 \%$ at five years and $70 \%$ at 10 years. However, the authors included patients with metastatic carcinoid tumors, pheochromocytoma, paraganglioma, medullary thyroid carcinoma and the data was independent of the histologic origin of the tumor. None of the patients showed CR, but total percentage of patients showing stable disease during the 32-month follow-up period was $82 \%$, which was similar to patients who received additional therapy combined with I-131 MIBG [83]. Although treatment of NETs with I-131 MIBG appears to be effective in symptomatic relief, further randomized studies are needed to evaluate its usefulness against chemotherapeutic agents. 


\section{Metastatic Bone Pain Palliation}

Bone pain caused by skeletal metastases from advanced cancers severely reduces patient quality of life. Approximately $65 \%$ of prostate or breast cancer and $35 \%$ of advanced lung, thyroid, and kidney cancer patients will experience symptoms [84]. In general, greater than $80 \%$ of the cases with bone metastases are associated with prostate and breast cancer [85].

Intravenous administration of Sr-89 chloride, Sm-153-lexidronam, and Re-186-etidronate have been approved in different countries for the treatment of bone pain arising from osteoblastic or mixed osseous metastases. Among these agents, Re-186-etidronate is approved in Europe while the others are approved in the US.

Sm-153-Lexidronam is the most commonly used radiopharmaceutical for bone pain palliation from metastatic disease. The molecule combines Sm-153 with calcium salt of ethylenediaminetetramethylenephosphonic acid (EDTMP). In addition to an energetic beta emission $(810 \mathrm{keV})$, it emits gamma photons of $103.2 \mathrm{keV}$ which make imaging possible.

In a comparison trial by Baczyk et al., with breast or prostate cancer patients, complete pain relief was seen in $40 \%$ of women and $40 \%$ of men treated using Sm-153, and $25 \%$ of women and $33 \%$ of men achieved complete relief with $\mathrm{Sr}-89$, which appears to be similarly effective. No pain relief was observed in $20 \%$ of these patients [86]. Liepe et al. compared the effect of treatment with Re-188-HEDP, Re-186-HEDP, Sm-153-EDTMP, and Sr-89 Chloride. In total, 73\% of patients reported pain relief (77\% after Re-188, 67\% after Re-186, 73\% after Sm-153, and 72\% after Sr-89; $P=0.268-0.846$ ). Overall, fifteen percent of the patients was able to discontinue their pain medications after the treatment [87].

Bone seeking radiopharmaceuticals are effective systemic treatment options in improving the quality of life and decreasing morbidity in patients with painful skeletal metastases. It is less commonly used nowadays due to availability of effective alternative pain management options.

\section{Treatment of Liver Tumors with Yttrium-90 Microspheres-An Example of Physical Targeting}

Liver is a common site for metastases from many primary neoplasms including colorectal carcinoma, pancreatic carcinoma, breast cancer, and neuroendocrine tumors. Tumor burden within the liver will affect the morbidity and mortality. In addition to traditional treatments, liver-directed methods include hepatic arterial infusion chemotherapy, conformal radiation, transarterial chemoembolization, radiofrequency ablation, and radioembolization with Y-90 microspheres [88]. Although the mechanism of delivery involves physical targeting, we have included it since it involves administration of a radiopharmaceutical.

Once the patient is determined to be a candidate for radioembolization with Y-90 microspheres, therapy planning must be carried out. This includes evaluation of target volume for the treatment and assurance of safety from the treatment using morphological imaging studies (CT and MRI), as well as functional imaging modalities (PET/CT and SPECT/CT). Dosimetry and physiologic shunts are assessed from imaging with Tc-99m labeled macroaggregated albumin (MAA) administered into the hepatic artery. Determination of arteriovenous anastomoses or physiologic shunts to the lungs is important in order to avoid radiation pneumonitis $[89,90]$. If shunting to the lungs is more than $10 \%$, the 
dose administration must be reduced. If there is a $>20 \%$ shunt, the treatment with Y-90 microspheres should not be performed [91].

Radioembolization with Y-90 microspheres is a promising treatment option for liver tumors with overall response rates of $27-100 \%$ as assessed by clinical and/or FDG-PET criteria [91-94]. Multidisciplinary approach and caution regarding patient selection and treatment preparation is particularly important to avoid serious side effects and toxicity associated with this efficacious treatment.

\section{Conclusions}

In this article we have presented a brief review of commonly used targeted radionuclide therapeutic agents. We believe that changes in targeted radiotherapy will continue to improve alongside of progress in tumor biology research. Many institutions are formulating sophisticated radiopharmaceuticals including antibodies, fusion proteins, peptides and small organic molecules as well as sodium iodide gene transfer into tumor cells for diagnostic and therapeutic purposes.

In the end, the rules in radiobiology should be exploited, in particular, radiosensitivity during G2 and mitotic phases of the cell cycle. Hence, a reasonable approach would be to select a radiolabeled agent with an effective half-life comparable to the doubling time of the tumor cells, which may be estimated from a cell culture derived from a biopsy or less precisely from imaging. Unfortunately, this approach is not practical in using long-lived isotopes due to the dosimetry of radiation burden. An alternative approach is to do serial treatments synchronized to the tumor's native biological clock or with an adjuvant cell cycle arresting agent. Randomized studies are needed to evaluate the effectiveness and practicality of this approach.

\section{References}

1. Hajdu, S.I. 2000 years of chemotherapy of tumors. Cancer 2005, 103, 1097-1102.

2. DeVita, V.T., Jr. The influence of information on drug resistance on protocol design: The Harry Kaplan Memorial Lecture given at the Fourth International Conference on Malignant Lymphoma, June 6-9, 1990, Lugano, Switzerland. Ann. Oncol. 1991,2, 93-106.

3. Volkert, W.A.; Goeckeler, W.F.; Ehrhardt, G.J.; Ketring, A.R. Therapeutic radionuclides: Production and decay property considerations. J. Nucl. Med. 1991, 32, 174-185.

4. Hoefnagel, C.A. Radionuclide cancer therapy. Ann. Nucl. Med. 1998, 12, 61-70.

5. Koppe, M.; Postema, E.; Aarts, F.; Oyen, V.J.G.; Bleichrodt, R.P.; Boerman, O.J. Antibody-guided radiation therapy of cancer. Cancer Metastasis Rev. 2005, 24, 539-567.

6. Middendorp, M.; Grünwald, F. Update on recent developments in the therapy of differentiated thyroid cancer. Semin. Nucl. Med. 2010, 40, 145-152.

7. Schmutzler, C.; Kohrle, J. Implications of the molecular characterization of the sodium-iodide symporter (NIS). Exp. Clin. Endocrinol. Diabetes 1998, 106, S1-S10.

8. Dohan, O.; De la Vieja, A.; Paroder, V.; Riedel, C; Artani, M.; Reed, M.; Ginter, C.S.; Carrasco, N. The sodium/iodide symporter (NIS): Characterization, regulation, and medical significance. Endocr. Rev. 2003, 24, 48-77. 
9. Cooper, D.; Doherty, G.; Haugen, B.; Kloos, R.T.; Lee, S.L.; Mandel, S.J.; Mazzaferri, E.L.; McIver, B.; Pacini, F.; Schlumberger, M.; Sherman, S.I.; Steward, D.L.; Tuttle, R.M. Revised American Thyroid Association Management Guidelines for Patients with Thyroid Nodules and Differentiated Thyroid Cancer. Thyroid 2009, 19, 1167-1214.

10. Kukulska, A.; Krajewska, J.; Gawkowska-Suwińska, M.; Puch, Z.; Paliczka-Cieslik, E.; Roskosz, J.; Handkiewicz-Junak, D.; Jarzab, M.; Gubała, M.; Jarzab, B. Radioiodine thyroid remnant ablation in patients with differentiated thyroid carcinoma (DTC): Prospective comparison of long-term outcomes of treatment with 30, 60 and $100 \mathrm{mCi}$. Thyroid. Res. 2010, 3, 9.

11. Pilli, T.; Brianzoni, E.; Capoccetti, F.; Castagna, M.G.; Fattori, S.; Poggiu, A.; Rossi, G.; Ferretti, F.; Guarino, E.; Burroni, L.; Vattimo, A.; Cipri, C.; Pacini, F. A comparison of 1850 MBq (50 $\mathrm{mCi})$ and $3700 \mathrm{MBq}(100 \mathrm{mCi})$ 131-iodine administered doses for recombinant TSH-stimulated postoperative thyroid remnant ablation in differentiated thyroid cancer. J. Clin. Endocrinol. Metab. 2007, 92, 3542-3546.

12. Maxon, H.R.; Smith, H.S. Radioiodine-131 in the diagnosis and treatment of metastatic well differentiated thyroid cancer. Endocrinol. Metab. Clin. North. Am. 1990, 19, 685-718.

13. Durante, C.; Haddy, N.; Baudin, E.; Leboulleux, S.; Hartl, D.; Travagli, J.P.; Caillou, B.; Ricard, M.; Lumbroso, J.D.; De Vathaire, F.; Schlumberger, M. Long term outcome of 444 patients with distant metastases from papillary and follicular thyroid carcinoma: Benefits and limits of radioiodine therapy. J. Clin. Endocrinol. Metab. 2006, 91, 2892-2899.

14. Maxon, H.R.; Englaro, E.E.; Thomas, S.R.; Hertzberg, Y.D.; Hinnefeld, J.D.; Chen, L.S.; Smith, H.; Cummings, D.; Aden, M.D. Radioiodine-131 therapy for well-differentiated thyroid cancer-A quantitative radiation dosimetric approach: Outcome and validation in 85 patients. $J$. Nucl. Med. 1992, 33, 1132-1136.

15. Lassmann, M.; Hänscheid, H.; Chiesa, C.; Hindorf, C.; Flux, G.; Luster, M. EANM Dosimetry Committee: Series on standard operational procedures for pre-therapeutic dosimetry I: Blood and bone marrow dosimetry in differentiated thyroid cancer therapy. Eur. J. Nucl. Med. Mol. Imaging 2008, 35, 1405-1412.

16. Luster, M.; Clarke, S.E.; Dietlein, M.; Lassmann, M.; Lind, P; Oyen, W.J.G.; Tennvall, J.; Bombardieri, E. Guidelines for radioiodine therapy of differentiated thyroid cancer. Eur. J. Nucl. Med. Mol. Imaging 2008, 35, 1941-1959.

17. Pacini, F.; Ladenson, P.W.; Schlumberger, M.; Driedger, A.; Luster, M.; Kloos, R.T.; Sherman, S.; Haugen, B.; Corone, C.; Molinaro, E.; Elisei, R.; Ceccarelli, C.; Pinchera, A.; Wahl, R.L.; Leboulleux, S.; Ricard, M.; Yoo, J.; Busaidy, N.L.; Delpassand, E.; Hanscheid, H.; Felbinger, R.; Lassmann, M.; Reiners, C. Radioiodine ablation of thyroid remnants after preparation with recombinant human thyrotropin in differentiated thyroid carcinoma: Results of an international, randomized, controlled study. J. Clin. Endocrinol. Metab. 2006, 91, 926-932.

18. Baudin, E.; Schlumberger, M. New therapeutic approaches for metastatic thyroid carcinoma. Lancet Oncol. 2007, 8, 148-156.

19. Hall, P.; Holm, L.E. Cancer in iodine-131 exposed patients. J. Endocrinol. Invest. 1995, 18, 147-149.

20. Rubino, C.; de Vathaire, F.; Dottorini, M.E. Second primary malignancies in thyroid cancer patients. Br. J. Cancer 2003, 89, 1638-1644. 
21. Horning, S.J. Treatment approaches to the low-grade lymphomas. Blood 1994, 83, 881-884.

22. Witzig, T.E. Efficacy and safety of Y-90 ibritumomab tiuxetan (Zevalin) radioimmunotherapy for non-Hodgkin's lymphoma. Semin. Oncol. 2003, 30, 11-16.

23. Kaminski, M.S.; Tuck, M.; Estes, J.; Kolstad, A.; Ross, C.W.; Zasadny, K.; Regan, D.; Kison, P.; Fisher, S.; Kroll, S.; Wahl, R.L. I-131-Tositumomab therapy as initial treatment for follicular lymphoma. N. Engl. J. Med. 2005, 352, 441-449.

24. Anderson, K.C.; Bates, M.P.; Slaughenhoupt, B.L.; Pinkus, G.S.; Schlossman, S.F.; Nadler, L.M. Expression of human B cell-associated antigens on leukemias and lymphomas: A model of human B cell differentiation. Blood 1984, 63, 1424-1433.

25. Tedder, T.F.; Boyd, A.W.; Freedman, A.S.; Nadler, L.M.; Schlossman, S.F. The B cell surface molecule B1 is functionally linked with B cell activation and differentiation. J. Immunol. 1985, 135, 973-979.

26. Cardarelli, P.M.; Quinn, M.; Buckman, D.; Fang, Y.; Kolcher, D.; King, D.; Bebbington, C.; Yarranton, G. Binding to CD20 by anti-B1 antibody or F(ab9)(2) is sufficient for induction of apoptosis in B-cell lines. Cancer Immunol. Immunother. 2002, 51, 15-24.

27. Stashenko, P.; Nadler, L.M.; Hardy, R.; Schlossman, S.F. Characterization of a human B lymphocyte-specific antigen. J. Immunol. 1980, 125, 1678-1685.

28. Oyen, W.J.G.; Bodel, L.; Giammarile, F.; Maecke, H.R.; Tennvall, J.; Luster, M.; Brans, B. Targeted therapy in nuclear medicine- current status and future prospects. Ann. Oncol. 2007, 18, 1782-1792.

29. Morschhauser, F.; Radford, J.; Van Hoof, A.; Vitolo, U.; Soubeyran, P.; Tilly, H.; Huijgens, P.C.; Kolstad, A.; d'Amore, F.; Diaz, M.G.; Petrini, M.; Sebban, C.; Zinzani, P.L.; van Oers, M.H.J.; van Putten, W.; Bischof-Delaloye, A.; Rohatiner, A.; Salles, G.; Kuhlmann, J.; Hagenbeek, A . Phase III trial of consolidation therapy with yttrium-90-ibritumomab tiuxetan compared with no additional therapy after first remission in advanced follicular lymphoma. J. Clin. Oncol. 2008, 26, 5156-5164.

30. de Labriolle-Vaylet, C.; Cattan, P.; Sarfati, E.; Wioland, M.; Billotey, C.; Broche'riou, C.; Rouvier, E.; de Roquancourt, E.; Roste`ne, W.; Askienazy, S.; Barbet, J.; Milhaud, G.; Gruaz-Guyon, A. Successful Surgical Removal of Occult Metastases of Medullary Thyroid Carcinoma Recurrences with the Help of Immunoscintigraphy and Radioimmunoguided Surgery. Clin. Cancer Res. 2000, $6,363-371$.

31. Witzig, T.E.; Gordon, L.I.; Cabanillas, F.; Czuczman, M.S.; Emmanouilides, C.; Joyce, R.; Pohlman, B.L.; Bartlett, N.L.; Wiseman, G.A.; Padre, N.; Grillo-López, A.J.; Multani, P.; White, C.A. Randomized controlled trial of yttrium-90-labeled ibritumomab tiuxetan radioimmunotherapy versus rituximab immunotherapy for patients with relapsed or refractory low-grade, follicular, or transformed B-cell non-Hodgkin's lymphoma. J. Clin. Oncol. 2002, 20, 2453-2463.

32. Kaminski, M.S.; Zelenetz, A.D.; Press, O.W.; Saleh, M.; Leonard, J.; Fehrenbacher, L.; Lister, T.A.; Stagg, R.; Tidmarsh, G.F.; Kroll, S.; Wahl, R.L.; Knox, S.J.; Vose, J.M. Pivotal Study of Iodine I 131 Tositumomab for Chemotherapy-Refractory Low-Grade or Transformed Low-Grade B-Cell Non-Hodgkin's Lymphomas. J. Clin. Oncol. 2001, 19, 3918-3928.

33. Zelenetz, A.D. Radioimmunotherapy for lymphoma. Curr. Opin. Oncol. 1999, 11, 375-380. 
34. Wahl, R.L.; Kroll, S.; Zasadny, K.R. Patient-specific whole-body dosimetry: Principles and a simplified method for clinical implementation. J. Nucl. Med. 1998, 39, S14-S20.

35. Rajendran, J.; Gopal, A.; Fisher, D.; Durack, L.D.; Gooley, T.A.; Press, O.W. Myeloablative I-131-tositumomab radioimmunotherapy in treating non-hodgkin's lymphoma: Comparison of dosimetry based on whole-body retention and dose to critical organ receiving the highest dose. J. Nucl. Med. 2008, 49, 837-844.

36. Kaminski, M.S.; Estes, J.; Zasadny, K.R.; Francis, I.R.; Ross, C.W.; Tuck, M.; Regan, D.; Fisher, S.; Gutierrez, J.; Kroll, S.; Stagg, R.; Tidmarsh, G.; Wahl, R.L. Radioimmunotherapy with iodine 131I tositumomab for relapsed or refractory B-cell non-Hodgkin lymphoma: Updated results and long-term follow-up of the University of Michigan experience. Blood 2000, 96, 1259-1266.

37. Witzig, T.E.; Flinn, I.W.; Gordon, L.I.; Emmanouilides, C.; Czuczman, M.S.; Saleh, M.N.; Cripe, L.; Wiseman, G.; Olejnik, T.; Multani, P.; White, C.A. Treatment with ibritumomab tiuxetan radioimmunotherapy in patients with rituximab-refractory follicular non- Hodgkin's lymphoma. J. Clin. Oncol. 2002, 20, 3262-3269.

38. Kaminski, M.S.; Zasadny, K.R.; Francis, I.R.; Milik, A.W.; Ross, C.W.; Moon, S.D.; Crawford, S.M.; Burgess, J.M.; Petry, N.A.; Butchko, G.M.; Glenn, S.D.; Wahl, R.L. Radioimmunotherapy of B-cell lymphoma with [131I] anti-B1 (anti-CD20) antibody. N. Engl. J. Med. 1993, 329, 459-465.

39. Witzig, T.E.; White, C.A.; Wiseman, G.A.; Gordon, L.I.; Emmanouilides, C.; Raubitschek, A.; Janakiraman, N.; Gutheil, J.; Schilder, R.J.; Spies, S.; Silverman, D.H.S.; Parker, E.; Grillo-Lo'pez, A.J. Phase I/II trial of IDEC-Y2B8 radioimmunotherapy for treatment of relapsed or refractory CD20(+) B-cell non-Hodgkin's lymphoma. J. Clin. Oncol. 1999, 17, 3793-3803.

40. Vose, J.M.; Wahl, R.L.; Saleh, M.; Rohatiner, A.; Knox, S.J.; Radford, J.A.; Zelenetz, A.D.; Tidmarsh, G.F.; Stagg, R.J.; Kaminski, M.S. Multicenter phase II study of iodine-131 tositumomab for chemotherapy-relapsed/refractory low-grade and transformed low-grade B-cell non-Hodgkin's lymphomas. J. Clin. Oncol. 2000, 18, 1316-1323.

41. Horning, S.J.; Younes, A.; Jain, V.; Kroll, S.; Lucas, J.; Podoloff, D.; Goris, M. Efficacy and safety of tositumomab and iodine-131 tositumomab (Bexxar) in B-cell lymphoma, progressive after rituximab. J. Clin. Oncol. 2005, 23, 712-719.

42. Song, H.; Du, Y.; Sgouros, G.; Prideaux, A.; Frey, E.; Wahl, R.L. Therapeutic potential of 90Y-and 131I-labeled anti-CD20 monoclonal antibody in treating non- Hodgkin's lymphoma with pulmonary involvement: A Monte Carlo-based dosimetric analysis. J. Nucl. Med. 2007, 48, 150-157.

43. Jacene, H.; Filice, R.; Kasecamp, W.; Wahl, R.L. Comparison of 90Y-Ibritumomab Tiuxetan and 131I-Tositumomab in Clinical Practice. J. Nucl. Med. 2007, 48, 1767-1776.

44. Storto, G.; De Renzo, A.; Pellegrino, T.; Perna, F.; de Falco, T.; Erra, P.; Nardelli, A.; Speranza, A.; Klain, M.; Rotoli, B.; Pace, L. Assessment of Metabolic Response to Radioimmunotherapy with 90 Y-Ibritumomab Tiuxetan in Patients with Relapsed or Refractory B-Cell Non-Hodgkin Lymphoma. Radiology 2010, 254, 245-252. 
45. Fisher, R.I.; Kaminski, M.S.; Wahl, R.L.; Knox, S.J.; Zelenetz, A.D.; Vose, J.M.; Leonard, J.P.; Kroll, S.; Goldsmith, S.J.; Coleman, M. Tositumomab and iodine-131 tositumomab produces durable complete remissions in a subset of heavily pretreated patients with low grade and transformed non-Hodgkin's lymphomas. J. Clin. Oncol. 2005, 23, 7565-7573.

46. Armitage, J.O.; Carbone, P.P.; Connors, J.M.; Levine, A.; Bennett, J.M.; Kroll, S. Treatment-related myelodysplasia and acute leukemia in non-Hodgkin's lymphoma patients. J. Clin. Oncol. 2003, 21, 897-906.

47. Bennett, J.; Kaminski, M.; Leonard, J.; Vose, J.M.; Zelenetz, A.D.; Knox, S.J.; Horning, S.; Press, O.W.; Radford, J.A.; Kroll, S.M.; Capizzi, R.L. Assessment of treatment-related myelodysplastic syndromes and acute myeloid leukemia in patients with non-Hodgkin lymphoma treated with tositumomab and iodine I131 tositumomab. Blood 2005, 105, 4576-4582.

48. Krenning, E.P.; Breeman, W.A.P.; Kooij, P.P.M.; Lameris, J.S.; Bakker, W.H.; Koper, W.; Ausema, L.; Reubi, J.C.; Lamberts, S.W.J. Localisation of endocrine-related tumours with radioiodinated analogue of somatostatin. Lancet 1989, 1, 242-244.

49. Krenning, E.P.; Kooij, P.P.; Bakker, W.H.; Breeman, W.A.P.; Postema, P.T.E.; Kwekkeboom, D.J.; Oei, H.Y.; De Jong, M.; Visser, T.J.; Reijs, A.E.M.; Lamberts, S.W.J. Radiotherapy with a radiolabeled somatostatin analogue, [111In-DTPA-D-Phe1]-octreotide: A case history. Ann. N. Y. Acad. Sci. 1994, 733, 496-506.

50. McCarthy, K.E.; Woltering, E.A.; Espenan, G.D.; Cronin, M.; Maloney, T.J.; Anthony, L.B. In situ radiotherapy with 111 In-Pentreotide: Initial observations and future directions. Cancer J. Sci. Am. 1998, 4, 94-102.

51. De Jong, M.; Breeman, W.A.; Bernard, H.F.; Kooij, P.P.; Slooter, G.D.; Van Eijck, C.H.; Kwekkeboom, D.J.; Valkema, R.; Macke, H.R.; Krenning, E.P. Therapy of neuroendocrine tumors with radiolabeled somatostatin-analogues. Q. J. Nucl. Med. 1999, 43, 356-366.

52. McCarthy, K.E.; Woltering, E.A.; Anthony, L.B. In situ radiotherapy with 111In-pentetreotide: State of the art and perspectives. Q. J. Nucl. Med. 2000, 44, 88-95.

53. Otte, A.; Jermann, E.; Behe, M.; Goetze, M.; Bucher, H.C.; Roser, H.W.; Heppeler, A.; Mueller-Brand, J.; Maecke, H.R. DOTATOC: A powerful new tool for receptor-mediated radionuclide therapy. Eur. J. Nucl. Med. 1997, 24, 792-795.

54. Waldherr, C.; Pless, M.; Maecke, H.R.; Haldermann, A.; Mueller-Brand, J. The clinical value of [90YDOTA]- D-Phe1-Tyr3-octreotide (90Y-DOTATOC) in the treatment of neuroendocrine tumours: A clinical phase II study. Ann. Oncol. 2001, 12, 941-945.

55. Paganelli, G.; Bodei, L.; Handkiewicz, D.J.; Rocca, P.; Papi, S.; Lopera, S.M.; Gatti, M.; Chinol, M.; Bartolomei, M.; Fiorenza, M.; Grana, C. 90Y-DOTA-D-Phe1-Try3-octreotide in therapy of neuroendocrine malignancies. Biopolymers 2002, 66, 393-398.

56. Virgolini, I.; Traub, T.; Novotny, C.; Leimer, M.; Fuger, B.; Li, S.R.; Patri, P.; Pangerl, T.; Angelberger, P.; Raderer, M.; Andreae, F.; Kurtaran, A.; Dudczak, R. New trends in peptide receptor radioligands. Q. J. Nucl. Med. 2001, 45, 153-159.

57. Kwekkeboom, D.J.; Kam, B.L.; Bakker, W.H.; Kooij, P.P.M; de Herder, W.W.; Srinivasan, A.; Erion, J.L.; Bugaj, J.L.; Schmidt, M.A.; de Jong, M.; Krenning, E.P. Treatment with Lu-177-DOTA-Tyr3-octreotate in patients with somatostatin receptor positive tumors: Preliminary results. Eur. J. Nucl. Med. 2001, 28S, Abstract 1027P. 
58. Kwekkeboom, D.J.; Kam, B.L.; Bakker, W.H.; Kooij, P.P.M; de Herder, W.W.; Srinivasan, A.; Erion, J.L.; Bugaj, J.L.; Schmidt, M.A.; de Jong, M.; Krenning, E.P. Treatment with Lu-177-DOTA-Tyr3-octreotate in patients with somatostatin receptor positive tumors. $J$. Nucl. Med. 2002, 43S, 34P.

59. Kulke, M. Neuroendocrine Tumors: Is There a Standard Treatment?Gastrointest. Cancer Res. 2008, 2, 152-153.

60. Valkema, R.; De Jong, M.; Bakker, W.H.; Breeman, W.A.; Kooij, P.P.; Lugtenburg, P.J.; De Jong, F.H.; Christiansen, A.; Kam, B.L.; De Herder, W.W.; Stridsberg, M.; Lindemans, J.; Ensing, G.; Krenning, E.P. Phase I study of peptide receptor radionuclide therapy with [In- DTPA] octreotide: the Rotterdam experience. Semin. Nucl. Med. 2002, 32, 110-122. Anthony, L.B.; Woltering, E.A.; Espanan, G.D.; Cronin, M.; Maloney, T.J.; McCarthy, K.E. Indium-111- pentetreotide prolongs survival in gastroenteropancreatic malignancies. Semin. Nucl. Med. 2002, 32, 123-132.

62. Balster, D.A.; O'Dorisio, M.S.; Summers, M.S.; Turman, M.A. Segmental expression of somatostatin receptor subtypes sst1 and sst2 in tubules and glomeruli of human kidney. Am. J. Physiol. Renal. Physiol. 2001, 280, F457-F465.

63. Valkema, R.; Pauwels, S.; Kvols, L.K.; Barone, R.; Jamar, F.; Bakker, W.H.; Kwekkeboom, D.J.; Bouterfa, H.; Krenning, E.P. Survival and response after peptide receptor radionuclide therapy with [90Y-DOTA0,Tyr3]octreotide in patients with advanced gastroenteropancreatic neuroendocrine tumors. Semin. Nucl. Med. 2006, 36, 147-156.

64. Bushnell, D.; O’Dorisio, T.; Menda, Y.; Carlisle, T.; Zehr, P.; Connolly, P.; Karwal, M.; Miller, S.; Parker, S.; Bouterfa, H. Evaluating the clinical effectiveness of 90Y-SMT 487 in patients with neuroendocrine tumors. J. Nucl. Med. 2003, 44, 1556-1560.

65. Kwekkeboom, D.J.; Bakker, W.H.; Kooij, P.P.; Konijnenberg, M.W.; Srinivasan, A.; Erion, J.; Schmidt, M.A.; Bugaj, J.L.; De Jong, M.; Krenning, E.P. [177Lu DOTA0Tyr3]octreotate: Comparison with [111In-DTPA0]octreotide in patients. Eur. J. Nucl. Med. 2001, 28, 1319-1325.

66. Kwekkeboom, D.J.; de Herder, W.W.; Kam, B.L.; van Eijck, C.H.; van Essen, M.; Kooij, P.P.; Feelders, R.A.; van Aken, M. O.; Krenning, E.P. Treatment with the radiolabeled somatostatin Analog [177Lu-DOTA0,Tyr3]octreotate: Toxicity, efficacy, and survival. J. Clin. Oncol. 2008, 26, 2124-2130.

67. Kwekkeboom, D.J.;Krenning, E.P.; Lebtahi, R.; Komminoth, P.; Kos-Kudla, B.; de Herder, W.W.; Plockinger, U. ENETS Consensus guidelines for the standards of care in neuroendocrine tumors: Peptide receptor radionuclide therapy with radiolabeled somatostatin analogs. Neuroendocrinology 2009, 90, 220-226.

68. Simon, D.; Korber, C.; Krausch, M.; Segering, J.; Groth, P.; Gorges, R.; Grunwald, F.; Muller-Gartner, H.W.; Schmutzler, C.; Kohrle, J.; Roher, H.D.; Reiners, C. Clinical impact of retinoids in redifferentiation therapy of advanced thyroid cancer: Final results of a pilot study. Eur. J. Nucl. Med. 2002, 29, 775-782.

69. Gruning, T.; Tiepolt, C.; Zophel, K.; Bredow, J.; Kropp, J.; Franke, W.G. Retinoic acid for redifferentiation of thyroid cancer-does it hold its promise? Eur. J. Endocrinol. 2003, 148, 395-402.

70. Kohlfuerst, S.; Igerc, I.; Gallowitsch, H.J.; Gomez, I.; Kresnik, E.; Matschnig, S.; Lind, P. Is there a role for sandostatin treatment in patients with progressive thyroid cancer and iodine-negative but somatostatin-receptor-positive metastases? Thyroid 2006, 16, 1113-1119. 
71. Hattner, R.S.; Huberty, J.P.; Engelstad, B.L.; Gooding, C.A.; Ablin, A.R. Localization of m-iodo (I-131) benzylguanidine in neuroblastoma. Am. J. Roentgenol. 1984, 143, 373-374.

72. Nakajo, M.; Shapiro, B.; Copp, J.; Kalff, V.; Gross, M.D.; Sisson, J.C.; Beierwaltes, W.H. The normal and abnormal distribution of the adrenomedullary imaging agent $\mathrm{m}[\mathrm{I}-131]$ iodobenzylguanidine (I-131 MIBG) in man: Evaluation by scintigraphy. J. Nucl. Med. 1983, 24, 672-682.

73. Shapiro, B.; Copp, J.E.; Sisson, J.C.; Eyre, P.L.; Wallis, J.; Beierwaltes, W.H. Iodine-131 metaiodobenzylguanidine for the locating of suspected pheochromocytomas: Experience in 400 cases. J. Nucl. Med. 1985, 26, 576-585.

74. Grünwald, F.; Ezziddin, S. I-131 Metaiodobenzylguanidine therapy of neuroblastoma and other neuroendocrine tumors. Semin. Nucl. Med. 2010, 40, 153-163.

75. Wafelman, A.R.; Nortier, Y.L.; Rosing, H.; Maessen, H.J.M.; Taal, B.G.; Hoefnagel, C.A.; Maes, R.A.A.; Beijnen, J.H. Renal excretion of metaiodobenzylguanidine after therapeutic doses in cancer patients and its relation to dose and creatinine clearance. Nucl. Med. Commun. 1995, 16, 767-772.

76. Ehninger, G.; Klingebiel, T.; Kumbier, I.; Schuler, U.; Feine, U.; Treuner, J.; Waller, H.D. Stability and pharmacokinetics of m-131I-iodobenzylguanidine in patients. Cancer Res. 1987, 47, 6147-6149.

77. Matthay, K.K.; Yanik, G.; Messina, J.; Quach, A.; Huberty, J.; Cheng, S.; Veatch, J.; Goldsby, R.; Brophy, P.; Kersun, L.S.; Hawkins, R.A.; Maris, J.M. Phase II study on the effect of disease sites, age, and prior therapy on response to iodine 131 metaiodobenzylguanidine therapy in refractory neuroblastoma. J. Clin. Oncol. 2007, 25, 1054-1060.

78. Chrisoulidou, A.; Kaltsas, G.; Ilias, I.; Grossman, A.B. The diagnosis and management of malignant phaeochromocytoma and paraganglioma. Endocr Relat Cancer 2007, 14, 569-585.

79. Gedik, G.; Hoefnagel, C.; Bais, E.; Olmos, R.A. 131I-MIBG therapy in metastatic phaeochromocytoma and paraganglioma. Eur. J. Nucl. Med.Mol. Imaging 2008, 35, 725-733.

80. Castellani, M.R.; Seregni, E.; Maccauro, M.; Chiesa, C.; Aliberti, G.; Orunesu, E.; Bombardieri, E. MIBG for diagnosis and therapy of medullary thyroid carcinoma: Is there still a role? $Q . J . N u c l$. Med. Mol. Imaging 2008, 52, 430-440.

81. Safford, S.D.; Coleman, R.E.; Gockerman, J.P.; Moore, J.; Feldman, J.; Onaitis, M.W.; Tyler, D.S.; Olson, J.A.Jr. Iodine-131 metaiodobenzylguanidine treatment for metastatic carcinoid. Results in 98 patients. Cancer 2004, 101, 1987-1993.

82. Taal, B.G.; Hoefnagel, C.A.; Valdes Olmos, R.A.; Boot, H.; Beijnen, J.H. Palliative effect of metaiodobenzylguanidine in metastatic carcinoid tumors. J. Clin. Oncol. 1996, 14, 1829-1838.

83. Mukherjee, J.J.; Kaltsas, G.A.; Islam, N.; Plowman, P.N.; Foley, R.; Hikmat, J.; Britton, K.E.; Jenkins, P.J.; Chew, S.L.; Monson, J.P.; Besser, G.M.; Grossman, A.B. Treatment of metastatic carcinoid tumours,phaeochromocytoma, paraganglioma and medullary carcinoma of the thyroid with 131I-meta-iodobenzylguanidine (131I-mIBG). Clin. Endocrinol. 2001, 55, 47-60.

84. Paes, F.; Serafini, A. Systemic metabolic radiopharmaceutical therapy in the treatment of metastatic bone pain.Semin. Nucl. Med. 2010, 40, 89-104. 
85. Lam, M.G.; de Klerk, J.M.; van Rijk, P.P.; Zonnenberg, B.A. Bone seeking radiopharmaceuticals for palliation of pain in cancer patients with osseous metastases. Anticancer Agents Med. Chem. 2007, 7, 381-397.

86. Baczyk, M.; Czepczynski, R.; Milecki, P.; Pisarek, M.; Oleksa, R.; Sowinski, J. 89Sr versus 153SmEDTMP: Comparison of treatment efficacy of painful bone metastases in prostate and breast carcinoma. Nucl. Med. Commun. 2007, 28, 245-250.

87. Liepe, K.; Kotzerke, J. A comparative study of 188Re-HEDP, 186Re- HEDP, 153Sm-EDTMP and $89 \mathrm{Sr}$ in the treatment of painful skeletal metastases. Nucl. Med. Commun. 2007, 28, 623-630.

88. Mulcahy, M.F.; Lewandowski, R.J.; Ibrahim, S.M.; Sato, K.T.; Ryu, R.K.; Atassi, B.; Newman, S.; Talamonti, M.; Omary, R.A.; Benson, A. 3rd.; Salem, R. Radioembolization of colorectal hepatic metastases using yttrium-90 microspheres. Cancer 2009, 115, 1849-1858.

89. Sirtex Medical Limited. Sirtex medical training manual, training program physicians and institutions. Australia. Available online: http://www.sirtex.com/files/US20Package20Insert1.pdf (accessed on 6 March 2011).

90. Leung, T.W.; Lau, W.Y.; Ho, S.K.; Ward, S.C.; Chow, J.H.; Chan, M.S.; Metreweli, C.; Johnson, P.J.; Li, A.K. Radiation pneumonitis after selective internal radiation treatment with intraarterial 90yttrium-microspheres for inoperable hepatic tumors. Int. J. Radiat. Oncol. Phys. 1995, 33, 919-924.

91. Ibrahim, S.M.; Mulcahy, M.F.; Lewandowski, R.J.; Sato, K.T.; Ryu, R.K.; Masterson, E.J.; Newman, S.B.; Benson, A. 3rd.; Omary, R.A.; Salem, R. Treatment of unresectable cholangiocarcinoma using yttrium-90 microspheres: Results from a pilot study. Cancer 2008, 113, 2119-2128.

92. Coldwell, D.M.; Kennedy, A.S.; Nutting, C.W. Use of yttrium-90 microspheres in the treatment of unresectable hepatic metastases from breast cancer. Int. J. Radiat. Oncol. Phys. 2007, 69, 800-804.

93. Kennedy, A.S.; Dezarn, W.A.; McNeillie, P.; Coldwell, D.; Nutting, C.; Carter, D.; Murthy, R.; Rose, S.; Warner, R.R.; Liu, D.; Palmedo, H.; Overton, C.; Jones, B.; Salem, R. Radioembolization for unresectable neuroendocrine hepatic metastases using resin Y-90- microspheres: Early results in 148 patients. Am. J. Clin. Oncol. 2008, 31, 271-279.

94. Kalinowski, M.; Dressler, M.; Konig, A.; König, A.; El-Sheik, M.; Rinke, A.; Höffken, H.; Gress, T.M.; Arnold, R.; Klose, K.J.; Wagner, H.J. Selective internal radiotherapy with Yttrium-90 microspheres for hepatic metastatic neuroendocrine tumors: A prospective single center study. Digestion 2009, 79, 137-142.

(C) 2011 by the authors; licensee MDPI, Basel, Switzerland. This article is an open access article distributed under the terms and conditions of the Creative Commons Attribution license (http://creativecommons.org/licenses/by/3.0/). 